\title{
Volatilities in the interdependence between stock market, bond market, and foreign exchange market in Vietnam: An empirical investigation
}

\author{
NGUYEN KHAC QUOC BAO \\ University of Economics HCMC - nguyenbao@ueh.edu.vn \\ BUI VAN HOANG \\ hvbuikt@gmail.com
}

\begin{abstract}
ARTICLE INFO
ABSTRACT
\end{abstract}

Article history:

Received:

Apr. 8, 2016

Received in revised form:

Jul. 8, 2016

Accepted:

Mar. 31, 2017

Keywords:

Exchange rate

Stock market

Volatility shifts

Spillover effects
This study analyzes volatilities in the relations between stock market, bond market, and foreign exchange market in Vietnam from April 2014 through December 2015. Particularly, we address the questions of whether there exist sudden changes in correlations between the markets to respond to volatility shocks and whether these changes are temporary or extended. By using $\operatorname{VAR}(\mathrm{p})-\operatorname{FIEGARCH}(1, \mathrm{~d}, 1)-$ cDCC and PELT approaches in combination with a regression estimation with dummy variables, our empirical results validate the interdependence between the markets, which is found to vary over time. More importantly, volatility shocks give rise to sudden changes in their correlations, and at certain times these are long-lasting. Investors and policy makers in Vietnam should accordingly have due consideration of long-term spillovers. 


\section{Introduction}

For most investors and policy makers, perceiving the interdependence between markets is of crucial importance. Correlation structures of these markets act as a basis for formulating strategic policies and allocating investment portfolios. Economic analysts and fund management keep track of the fluctuations in correlations between assets to put forward investment guidelines in order to obtain excess profits. Given macroeconomic policy makers, analyses of the transmission channels between these markets play a major role in ensuring policy effectiveness and proper control over spillover effects in the economy.

Up to now a few studies have been conducted on the interdependence between interest rate, stock prices, and exchange rate in Vietnam. Huynh and Nguyen (2013) examined the linkages between VND/USD exchange rates, interest rates, and stock prices in Ho Chi Minh City, indicating the existing relation between the price of stock and rate of exchange. Meanwhile, Phan and Pham (2013) provide evidence that the interest rate and the exchange rate between VND and USD are negatively correlated with the stock price index. However, these studies have ended up considering whether an interdependence or a fixed correlation direction exists between these markets. To address this issue, therefore, this study not only provides evidence for the existence of the linkages between the stock market, bond market, and foreign exchange market in Vietnam, but also illustrates that their correlations are not stable but do change over time. More importantly, capturing the dynamism of these relations allows us to further examine shift-contagion effectssignificant changes in cross-asset correlations between consecutive variance states (Forbes \& Rigobon, 2002) to investigate whether market shocks have certain impacts on these correlations. It is crucial to understand the effects because in case of no existence of them, it is not imperative to adjust to proactive portfolios in the event of high volatilities, which thus helps increase the benefits from diversification of portfolio risk. Similarly, policy makers do not need to actively prevent the spillover effects of policies. In fact, if they do exist, it is essential to penetrate these effects or any shift contagion between markets for the purposes of hedging and financial stability or formulation of appropriate policies to steer the economy at will. Such policies occupy a very important role in limiting the impacts of the global crises on the national economy. Vietnam is a developing economy and is now witnessing a very high rate of integration, including financial integration. The opening of financial markets, as well as loosened policies 
in order to take a closer step to a market economy, is seen as a motive to accelerate the economic growth of the country.

However, besides the above advantages, accessing global financial flows is resulting in the very likelihood that Vietnam is vulnerable to contagious economic and financial problems such as crises, which will be fully discussed in the last section of this paper. That also means that financial market indicators will even fluctuate more and financial markets will suffer many more shocks when absorbing the fluctuations in regional and global markets. Therefore, in-depth analyses of the volatilities in the relations between stock, bond, and foreign exchange markets over the past decade are critical to both information gain and other new forecasts.

This paper does not only provide further evidence of the interdependence between financial market indicators but also contribute to the existing literature with full examination of the dynamism of the complicated relations between stock, bond, and foreign exchange markets in Vietnam. Furthermore, this is also the first to examine and provide valuable insights into the existence of volatility shift effects between the markets. Accordingly, volatility shocks of the markets strongly influence their relations, and, in particular, volatilities would also persist for a long time.

\section{Theoretical framework and relevant literature}

\subsection{Relation between stock market and bond market}

There have now been many different views on the nexus between interest rate and stock market indices. As traditionally argued, it is the discount that lies behind this relationship. Higher interest rates increase the opportunity cost of currency, reducing yields and stock prices. According to this approach, the interest rate is seen as a measure of the time value of money and a decisive factor to the price of stock. Hence, any changes in interest rates can also impede investment and have a negative impact on firms' profitability, thereby causing stock price fluctuations.

After a long time many scholars have found a negative correlation between these two markets (Shiller \& Beltratti, 1992). Recent studies, nevertheless, suggested evidence to argue against it in some particular cases. Andersen et al. (2007) and Bale (2010) concluded a negative correlation that exists only in a couple of early stages in a business cycle. The authors documented that a positive correlation appears as a result of cash flow effects, i.e. increased interest rates could lead to higher growth rates, and then firms could earn bigger profits in expansionary business cycles. Rigobon and Sack (2003) also had 
similar findings. As such, the direction of the correlation between these two markets can alter in response to the direction of the flow of information between them. This view was then advocated by Yang et al. (2009). Using a monthly dataset of dividends and bonds in the US and UK over the period of 150 years (1855-2001), they argued that stock-bond correlations change over time, depending on the economic cycle, inflation, and monetary policy. Hong et al. (2011) explained the similar case through income and substitution effects. Specifically, Bianconi et al. (2013) found that there are increases in conditional correlations of stock returns and bond returns in BRIC countries after the collapse of Lehman Brothers in September 2008. This result indicated the possibility that the relation between the two markets would be affected during sharp market volatilities.

\subsection{Relation between foreign ex- change market and bond market}

The connection between foreign exchange and bond markets has been explained by the theory of uncovered interest rate parity (UIP), according to which riskneutral investors will be indifferent to prevailing interest rates available in two countries as exchange rates between them are expected to be adjusted in order to exclude the incident of potential interest rate differences. Let $r_{f}$ be effective yield on investment abroad; $i_{h}$, domestic interest rate; $i_{f}$, foreign interest rate; $e_{f}$, the difference of the foreign currency appreciation and depreciation. We have:

$$
r_{f}=\left(1+i_{f}\right)\left(1+e_{f}\right)-1
$$

Assuming that foreign investment generates similar yields as domestic investment or $r_{f}=\left(1+i_{f}\right)\left(1+e_{f}\right)-1=i_{h}$ we have:

$$
e_{f}=\frac{\left(1+i_{h}\right)}{\left(1+i_{f}\right)}-1 \approx i_{h}-i_{f}
$$

Thus, to get the balance in interest rates between domestic investment and foreign investment, the difference of the foreign currency appreciation and depreciation must correspond to that in interest rates of the two countries. Specifically, if domestic interest rates are higher than foreign rates, the foreign currency will have to appreciate to offset lower interest rates, and the opposite is also true.

Lothian and $\mathrm{Wu}$ (2011) suggested that in short terms UIP only suffers a small bias, which, however, will be greater in the long run. Nevertheless, consistence in results of empirical investigations into the nexus has yet to be obtained. Bautista (2003) examined the interest rate-exchange rate interaction using dynamic conditional correlation estimator for the case of the Philippines. A strong positive 
correlation was shown during periods of high market fluctuations, especially during the 1997 economic crisis in East Asia and Southeast Asia. For another, Chinn and Meredith (2004) employed a sample of $\mathrm{G} 7$ countries over the period of 28 years, concluding the existence of a positive correlation between interest rates and exchange rates when considering long-run data, but this relation becomes negative given short-run data.

2.3. Relation between foreign exchange market and stock market

Existing literature suggests different patterns of interaction between the two markets. Consensus, however, has not been reached on existence of their connection and the direction of impact of stock market returns on exchange rate. In fact, commonly accepted has been the argument of Dornbush and Fisher (1980), whose reasoning is conditional on cash flows, suggesting a positive relation between exchange rate and the price of stock. As such, exchange rate is primarily measured by trade balance or current account balance of a country. The assumption is that fluctuations in exchange rate will affect international competitiveness and the balance of trade, and thus on real income and inputs. As argued by Joseph (2002) when domestic currency weakens, competitiveness of exports will increase, and the cost of imported inputs will decrease. Therefore, the depreciation of domestic currency should have positive (negative) effects on exporters (importers), which lead to a rise (reduction) in their stock prices, and the reverse is true.

Nevertheless, Branson (1983) and Frankel (1983) suggested that this relationship could be better explained by approaching stock prices. The authors documented that exchange rate is determined by supply and demand of key financial assets, such as stocks and bonds. There are two types of stock-oriented models: portfolio balance models and monetary models. Concerning the former, merely a negative relation exists between the price of stock and exchange rate. This model takes account of international portfolios diversified in the form of a function of exchange rate variation in the balance of supply and demand of domestic and international financial assets. Accordingly, an increase in domestic stock returns should result in domestic currency appreciation. On the other hand, monetary models maintain that the rates of exchange are assimilated into the prices of financial assets. The price of a financial asset is estimated by the current price of an expected cash flow, while exchange rate is determined by all macro factors that have effects on the expected value. As a result, in the event of an impact exerted by any basic factor on these two 
variables, the price of stock can affect (become affected by) the behavior of exchange rate.

Doong et al. (2005) examined the dynamic correlation between stocks and exchange rates of six Asian countries and territories in 1989-2003. Their results showed that stock returns are negatively related to simultaneous changes in exchange rates of all these countries except for Thailand. Lee et al. (2011) empirically investigated the interaction between the price of stock and rate of exchange of some Asia-Pacific countries using dynamic correlation. As indicated, the stock market-foreign exchange market correlation becomes stronger during increased stock market fluctuations. For a similar research setting, Yang et al. (2014) detected a negative correlation between the two markets. Meanwhile, Zhao (2010) analyzed the dynamic relation between real effective exchange rates and stock prices in China by employing VAR plus multivariate GARCH techniques. The results, however, suggested no existence of a longterm equilibrium for these two financial markets. For the case of Vietnam, Tran (2016) accumulated evidence to demonstrate a clear existence of interaction between the foreign exchange market and the stock market. The results of this study underpin both theoretical approaches men- tioned above, albeit with a focus on the linear trend between these two while ignoring their nonlinear relationship.

Review of earlier studies suggests that consistency in arguments over the nexus between these markets, especially the level of stability in their correlation over time, has not been achieved. The results from previous studies vary according to the economic status of each country and the methods employed for analyses. Examining the interdependence between the financial markets in such a country with many distinct characteristics as Vietnam is not always an easy task, irrespective of the results which does not truly reflect the reality. Thus, attempts to adopt new methods of analysis plus practical reference in this paper promise to address the issue more thoroughly.

\section{Methodology and data}

\subsection{Methodology}

To analyze the impact of volatility shocks on relationships between financial markets in Vietnam, we first survey responses of conditional dynamic correlations between such three financial market indicators as interest rate, exchange rate, and stock market index to market shocks. The study procedure comprises two phases. First, we estimate $\operatorname{VAR}(p)-\operatorname{FIEGARCH}(1, d, 1)-c$ DCC in 
three steps to obtain series of dynamic correlations between the markets. In the second phase, to identify the change points in residual series $\operatorname{ofVAR}(p)$, we adopt a pruned exact linear time (PELT) method. Then, regression sub models with dummy variables will be used to determine effects of volatility shocks on dynamic correlations between the markets.

$$
\begin{aligned}
& \operatorname{VAR}(p)-\text { FIEGARCH }(1, d, 1)-c D C C \\
& \text { process }
\end{aligned}
$$

Before the estimation of CDCC FIEGARCH $(1, d, 1)$ the data series should be filtered to obtain residuals with mean of zero as inputs for next estimations. Many filtering techniques have been proposed; this study uses $\operatorname{UVAR}(p)$ estimator as previously suggested by Dajcman and Kavkler (2012) and Sensoy and Sobaci (2014) to initially remove potential linear structures between the series. Another reason for using $\operatorname{VAR}(p)$ is that the data series of interest rates, exchange rates, and stock prices are closely connected, which need to be reflected into residuals to ensure the optimal estimated results. Thus, using VAR allows for the presence and participation of interactions between return series and exogenous lagged variables, which helps obtain dynamic factors more authentically and sufficiently. Specifically, this process starts with identification of the optimal lag length $p$ and estimation of unrestrictedVAR $(p)$ :

$$
r_{t}=\varphi_{0}+\emptyset_{1} r_{t-1}+\cdots+\emptyset_{p} r_{t-p}+\varepsilon_{t}
$$

where $r_{t}=\left[r_{1, t}, \ldots, r_{n, t}\right]^{\prime}$ denotes $n$-vector of asset returns, $p$ is lag length of VAR model, $\varphi_{0}$ is constant vector of length $n, \varnothing$ denotes coefficient matrix, and $\varepsilon_{t}=$ $\left[\varepsilon_{1, t}, \ldots, \varepsilon_{n, t}\right]^{\prime}$ represents vector of error terms. The estimated results at this stage will indicate the levels of interactions between series of returns, and provide initial statistics for determining periods with the presence of volatility change points.

In the second step, the error terms in $\operatorname{UVAR}(p)$ obtained from the first estimation are employed as inputs for estimating conditional volatilities $h_{i, t}$ using univariate $\operatorname{FIEGARCH}(1, d, 1)$ technique proposed by Bollerslev and Mikkelson (1996). Our aim is to determine the characteristics of the data series' volatilities. The reason for using FIEGARCH model $(1, d, 1)$ to estimate conditional volatilities lies in the common characteristics of financial time series such as being asymmetric, featuring long memory or leverage effect, and so on. With the econometric characteristics developed to be based on ARCH models and integrated into a single model, FIEGARCH is highly rated with good flexibility, intended to capture more features of the studied volatilities. Specifically, the following equation will be estimated: 
$\ln h_{i, t}=\omega+(1-\beta L)^{-1}(1-\alpha L)(1-$ $L)^{-d} g\left(\varepsilon_{-}(i, t-1)\right)$

with $g\left(\varepsilon_{i, t}\right)=\theta \varepsilon_{i, t}+\gamma\left(\left|\varepsilon_{i, t}\right|-\right.$ $\left.E\left|\varepsilon_{i, t}\right|\right)$ in which $\theta \varepsilon_{i, t}$ denotes sign effect (asymmetric response), $\quad\left(\gamma\left(\left|\varepsilon_{i, t}\right|-\right.\right.$ $\left.\left.E\left|\varepsilon_{i, t}\right|\right)\right)$ denotes magnitude effect (symmetric response) on $g\left(\varepsilon_{i, t}\right), L$ is a lag operator with $L^{k}\left(X_{t}\right)=X_{t-k}$, and $(1-L)^{d}$ is a financial differenced parameter.

In the third step, the results of covariance matrix achieved from the second one will be adopted in Aielli's (2013) corrected dynamic conditional correlation ( $c$ DCC ) model to measure dynamic correlation series between the markets. Let $E_{t-1}\left[\varepsilon_{t}\right]=0$ and $E_{t-1}\left[\varepsilon_{t} \varepsilon_{t}\right]=H_{t}$, where $E_{t}[\cdot]$ represents conditional expectation of $\varepsilon_{t}, \varepsilon_{t-1}$, etc., the conditional variance matrix of asset $H_{t}$ can be defined as:

$$
H_{t}=D_{t}^{1 / 2} R_{t} D_{t}^{1 / 2}
$$

where $R_{t}=\left[\rho_{i j, t}\right]$ is conditional correlation matrix, $D_{t}=\operatorname{diag}\left(h_{1, t}, \ldots, h_{n, t}\right)$ is diagonal matrix of conditional variances. Engle (2002) modeled the right side of the conditional variance equation $H_{t}$ suggesting a dynamic correlation structure labelled the DCC estimator as follows:

$$
\begin{aligned}
R_{t} & =\left\{Q_{t}^{*}\right\}^{-1 / 2} Q_{t}\left\{Q_{t}^{*}\right\}^{-1 / 2}, \\
Q_{t} & =(1-a-b) S+a u_{t-1} u_{t-1}+
\end{aligned}
$$
$b Q_{t-1}$. where $Q_{t} \equiv\left[q_{i j, t}\right], u_{t}=\left[u_{1, t}, \ldots, u_{n, t}\right]^{\prime}$, and $u_{i, t}$ denotes shift residuals, i.e. $u_{i, t}=$ $\frac{\varepsilon_{i, t}}{h_{i, t}}, S=\left[s_{i j}\right]=E\left[u_{t} u_{t}^{\prime}\right]$ is $n \times n$ unconditional covariance matrix, and $Q_{t}^{*}=$ $\operatorname{diag}\left\{Q_{t}\right\}$ and $a, b$ are non-negative scalars satisfying the condition $a+b<1$. Still, Aielli (2013) documented that the Q estimator in this way is inappropriate due to $E\left[R_{t}\right] \neq E\left[Q_{t}\right]$, and so advanced a more suitable model, $c$ DCC, as follows:

$$
Q_{t}=(1-a-b) S+a\left\{Q_{t-1}^{* 1 / 2} u_{t-1}^{\prime} u_{t-1} Q_{t-1}^{* 1 / 2}\right\}+b Q_{t-1}
$$

where $S$ is the unconditional covariance matrix of $Q_{t}^{* 1 / 2} u_{t}$. To ensure the stationarity, the following condition should be met, i.e. $a>0, b>0, a+b<1$. In the event of $a=b=0$, the conditional correlation is unchanged over time, and defined as below:

$$
\begin{aligned}
& \rho_{i j, t}= \\
& \frac{\left\{\omega_{i j, t-1}+a \varepsilon_{i, t-1} \varepsilon_{j, t-1}+b \rho_{i j, t-1}\right\}}{\sqrt{\left\{\omega_{i i, t-1}+a \varepsilon_{i, t-1}^{2}+b \rho_{i i, t-1}\right\}\left\{\omega_{j j, t-1}+a \varepsilon_{j, t-1}^{2}+b \rho_{j j, t-1}\right\}}} \\
& \text { with } \frac{\omega_{i j, t}=(1-a-b) s_{i j}}{\sqrt{q_{i i, t} q_{j j, t}}}
\end{aligned}
$$

\section{Pruned exact linear time (PELT)}

Identifying a change point in a data series refers to estimating the location (if any) at which the statistical features of the series vary. Assuming that we have a series with such a specific order as $y_{1: n}=$ $\left(y_{1}, \ldots, y_{n}\right)$, a change point is believed to exist in the series where there exists $\tau \in$ 
$\{1, \ldots, n-1\}$, at which the statistical features of $\left\{y_{1}, \ldots, y_{\tau}\right\}$ and $\left\{y_{\tau+1}, \ldots, y_{n}\right\}$ differ in one way or another. Most existing literature determines a set of change points by minimizing the function:

$$
\sum_{i=1}^{m+1}\left[c\left(y_{\tau_{i-1}+1}, \ldots, y_{\tau_{i}}\right)+\beta f(m)\right]
$$

where $C$ is a cost function of a segment, and $\beta f(m)$ is a penalty.

Several common types of algorithms developed to identify volatility change points include: (i) binary segmentation algorithm advanced by Edwards and Cavalli-Sforza (1965), Scott and Knott (1974), and Sen and Srivastava (1975); and (ii) segment neighborhood algorithm as was proposed by Auger and Lawrence (1989). The former, nonetheless, has been expected to provide less accuracy, yet has proven to be more beneficial in the case of less calculation volumes. On the other hand, the latter is more appreciated as regards the level of accuracy, but its requirements for large calculation volumes have appeared as a major drawback. For this reason Killick et al. (2012) postulated a brand new algorithm referred to as pruned exact linear time (PELT) and capitalizing (overcoming) the strengths (weaknesses) of the mentioned two. PELT, as has been demonstrated, not only offers similar or even better accuracy, compared to the segment neighborhood algorithm, but it is far more effective in terms of calculations.

\subsection{Data}

The study employs secondary data collected during the period from April 2004 to December 2015 with a total of 141 observations by month. In particular, the interest rate (IR) series includes monthly lending rate issued and calculated by the IMF. According to the IMF's calculations specifically for the case of Vietnam, it is estimated by taking the weighted average lending rate of the four largest commercial banks in the country. The stock price (VNI) series is represented by the closing price of the VN-Index for the final trading period at the end of each month. The central USD/VND rate announced by SBV is used as a proxy for exchange rate (USDVND).

\section{Results and discussion}

\subsection{Statistical description}

According to the descriptive statistics in Table 1, all the three return series are leftskewed with the skewness values being significant and larger than zero, while their kurtosis values (tailedness) are different from zero and statistically significant. The Jarque-Bera statistics once again confirm the nonstandard distribution of all of them at $1 \%$ significance level, rejecting the normal distribution assumption. ADF test results also reject the 
null hypothesis, indicating that the series

are all stationary at $1 \%$ level.

\section{Table 1}

Statistical description

\begin{tabular}{lccc}
\hline & IR & VNI & USDVND \\
\hline Min & -0.0474 & -0.3619 & -0.0057 \\
Mean & -0.0002 & 0.0087 & 0.0024 \\
Max & 0.0342 & 0.3851 & 0.0920 \\
Std. dev. & 0.0077 & 0.1034 & 0.0102 \\
\hline Skewness & $0.0102^{* * *}$ & 0.2000 & $6.2487 * * *$ \\
Kurtosis & $13.2850^{* * *}$ & $2.1138 * * *$ & $45.224 * * *$ \\
Jarque-Bera & $1038.1 * * *$ & $26.993 * * *$ & $12.841 * * *$ \\
\hline ADF (w/o const.) & $-4.8600^{* * *}$ & $-6.4324 * * *$ & $-5.9691 * * *$ \\
ADF (w. const.) & $-4.8447 * * *$ & $-6.4741 * * *$ & $-6.6598 * * *$ \\
ADF (w. const. \& trend) & $-4.8869 * * *$ & $-6.4659 * * *$ & $-6.6391 * * *$ \\
\hline Obs. & 140 & 140 & 140 \\
\hline
\end{tabular}

Note: $(*),(* *)$, and $(* * *)$ denote significance at $10 \%, 5 \%$, and $1 \%$ respectively.

As shown in Table 1, the average return of VN-Index from April 2004 through December 2015 amounts approximately to $0.87 \%$, and peaks at nearly $39 \%$ (early2007) (Figure 1). On the other hand, the riod.

USD/VND exchange rate reveals its average volatility rate of about $0.25 \%$ with a peak of $9.2 \%$ (early-2011). All the return series clearly exhibit the effects of the financial crisis as many largest volatilities can be recorded over the 2008-2010 pe- 

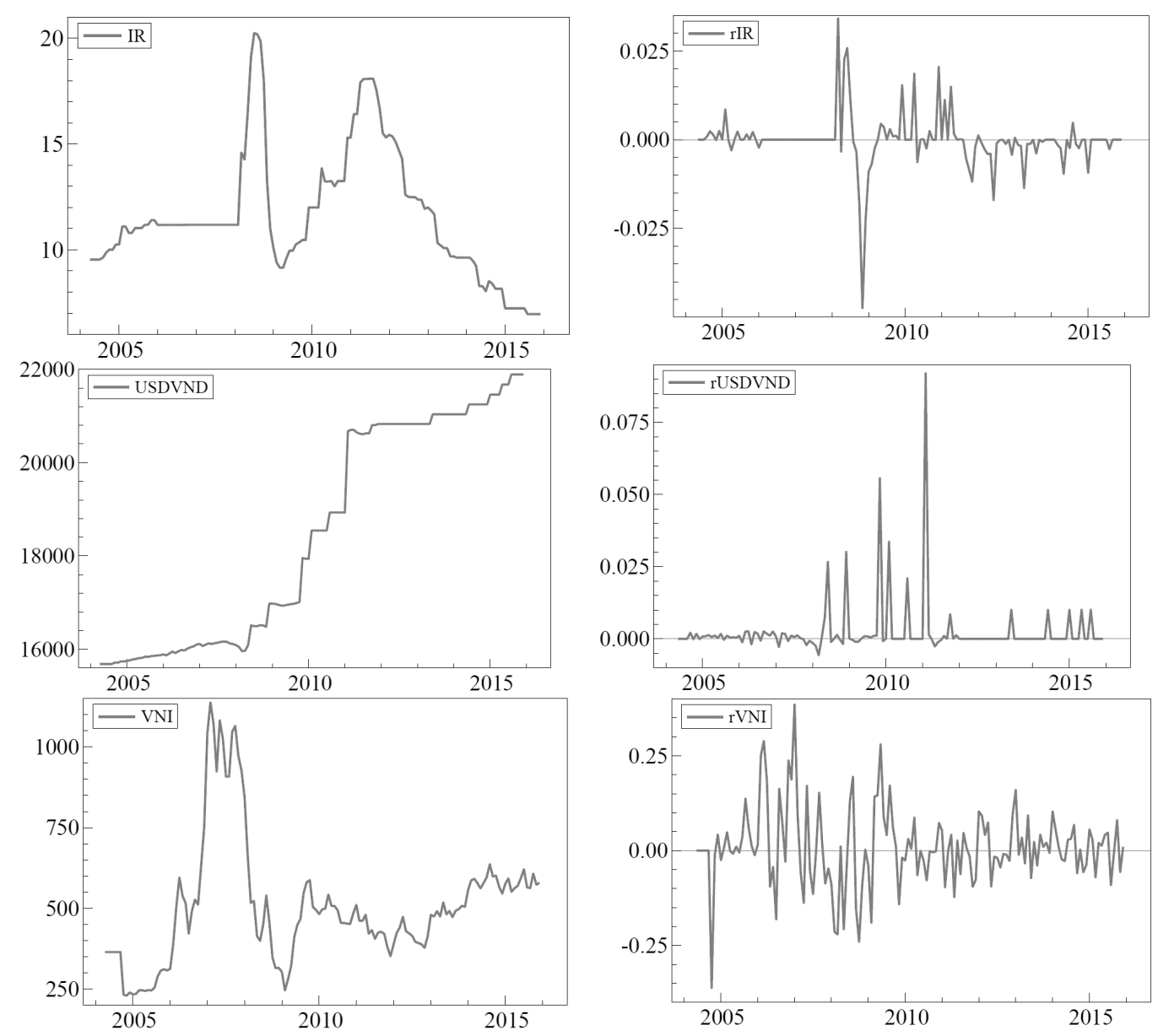

Figure 1. Real and spread values of USD/VND exchange rate, interest rate, and VNIndex between April 2004 and December 2015

4.2. Estimation results of $V A R-$ FIEGARCH - cDCC process

This process begins with the selection of the maximum lag length for $\operatorname{VAR}(\mathrm{p})$ model. The Bayesian indicators suggest that the optimal lag should be $p=1$. Also, we examine serial correlations of residuals using LM test. The VAR model becomes stable with $p=1$, where all roots are in the unit circle. The estimated results of coefficients of the VAR(1) presented in Table 2 demonstrate different levels of interpretation of lag series for the variables. In particular, return series of $\mathrm{VN}$-Index and interest rate depend primarily on their own lags with great statistical significance 


\section{Table 2}

Estimated coefficients of $\operatorname{VAR}(p)-\operatorname{FIEGARCH}(1, d, 1)-c$ DCC

\begin{tabular}{|c|c|c|c|}
\hline $\operatorname{VAR}(1)$ & $\mathrm{IR}_{t}$ & $\mathrm{VNI}_{t}$ & $\mathrm{USDVND}_{t}$ \\
\hline \multirow{2}{*}{$\mathrm{IR}_{t-1}$} & $0.3823 * * *$ & 0.5347 & -0.0968 \\
\hline & $(0.0000)$ & $(0.6299)$ & $(0.3989)$ \\
\hline \multirow{2}{*}{$\mathrm{VNI}_{t-1}$} & 0.0023 & $0.2953 * * *$ & -0.0018 \\
\hline & $(0.6962)$ & $(0.0005)$ & $(0.8340)$ \\
\hline \multirow{2}{*}{$\operatorname{USDVND}_{t-1}$} & 0.0538 & 0.3651 & -0.0335 \\
\hline & $(0.3745)$ & $(0.6648)$ & $(0.7007)$ \\
\hline \multirow{2}{*}{ Constant } & -0.0003 & 0.0054 & $0.0025 * * *$ \\
\hline & $(0.6747)$ & $(0.5433)$ & $(0.0063)$ \\
\hline $\operatorname{FIEGARCH}(1, d, 1)$ & IR & VNI & USDVND \\
\hline \multirow[t]{2}{*}{$\omega$} & $-126.5555 \times 10^{\wedge} 10^{* * *}$ & $-5.1884 * * *$ & 0.0594 \\
\hline & $(0.0000)$ & $(0.0000)$ & $(0.9944)$ \\
\hline \multirow[t]{2}{*}{ d } & $0.3474 * * *$ & $1.9172 * * *$ & $-0.2054 * * *$ \\
\hline & $(0.0000)$ & $(0.0000)$ & $(0.0000)$ \\
\hline \multirow[t]{2}{*}{$\alpha$} & $1.1468 * * *$ & $-1.1677 * * *$ & $3.4239 * * *$ \\
\hline & $(0.0000)$ & $(0.0000)$ & $(0.0000)$ \\
\hline \multirow[t]{2}{*}{$\beta$} & $-1.0150 * * *$ & $-0.7314 * * *$ & $0.9924 * * *$ \\
\hline & $(0.0000)$ & $(0.0000)$ & $(0.0000)$ \\
\hline \multirow[t]{2}{*}{$\theta$} & 0.6966 & $0.1318 * * *$ & $-0.5770 * * *$ \\
\hline & $(0.6840)$ & $(0.0000)$ & $(0.0000)$ \\
\hline \multirow[t]{2}{*}{$\gamma$} & $3.0979 * * *$ & $0.3594 * * *$ & $1.0240 * * *$ \\
\hline & $(0.0000)$ & $(0.0000)$ & $(0.0000)$ \\
\hline \multirow[t]{4}{*}{$c \mathrm{DCC}$} & Parameter & Coefficient & t-prob. \\
\hline & $\rho_{V N I, I R}$ & $0.2005 * *$ & 0.0319 \\
\hline & $\rho_{U S D V N D, I R}$ & -0.0325 & 0.8357 \\
\hline & $\rho_{U S D V N D, V N I}$ & $-0.2053 * *$ & 0.0128 \\
\hline
\end{tabular}




\begin{tabular}{cccc}
\hline $\operatorname{VAR}(1)$ & $\mathrm{IR}_{t}$ & $\mathrm{VNI}_{t}$ & $\mathrm{USDVND}_{t}$ \\
\hline$a$ & $0.5264 * * *$ & 0.0055 \\
$b$ & 0.0544 & 0.3394 \\
\hline
\end{tabular}

Note: $* * *, * *$, and $*$ denote significance of $1 \%, 5 \%$, and $10 \%$ respectively.

The results of residual tests for the VAR that the autoregressive conditional hetmodel suggest the existence of heteroske- eroskedasticity model be used to survey dasticity (Table 3). Thus, it is necessary volatilities of the data series

\section{Table 3}

Results of residual diagnostic tests for VAR model

\begin{tabular}{lcccc}
\hline & IR & VNI & USDVND & VAR \\
\hline AR 1-7 & $3.9704 * * *$ & 0.71270 & $1.8834 *$ & $1.3306^{*}$ \\
& $(0.0006)$ & $(0.6613)$ & $(0.0774)$ & $(0.0594)$ \\
ARCH 1-7 & 1.2872 & $3.1763 * * *$ & $0.0493(0.9998)$ & - \\
& $(0.2619)$ & $(0.0040)$ & & \\
Standard distribution & $210.14 * * *$ & $16.676 * * *$ & $2037.3000^{* * *}$ & $2078.5 * * *$ \\
test & $(0.0000)$ & $(0.0002)$ & $(0.0000)$ & $(0.0000)$ \\
Heteroskedasticity & $5.0034 * * *$ & 0.50654 & $0.0872(0.9975)$ & $1.4992 * * *$ \\
test & $(0.0001)$ & $(0.8025)$ & & $(0.0332)$ \\
\hline
\end{tabular}

Note: $* * *, * *$, and $*$ denote significance of $1 \%, 5 \%$, and $10 \%$ respectively.

The results of estimating the univariate FIEGARCH $(1, d, 1)$ model (Table 2) indicate that the parameter $(d)$ is different from zero and statistically significant, implying the existing persistence of the data series. The coefficients $\theta$ and $\gamma$ are statistically significant, implying the existing asymmetry of the volatilities of the data series. The estimated value of $\theta$ is negative for the case of the return series of exchange rate, whereas the results are posi- tive concerning the return series of Vn-Index and interest rate. This suggests that conditional volatilities are more likely to be affected by positive shocks than by negative ones with the same magnitude of the exchange rate, but the opposite is true given the stock and bond markets. Furthermore, the conditional volatility of the return series of interest rate is most powerfully impacted with the largest $\gamma$, yet that becomes weaker for the case of the return 
series of exchange rate and Vn-Index. Table 2 also shows the parameter $a$ is different from zero with high statistical significance, which rejects the hypothesis that the correlations between the series are unchanged. In addition, sum of the two parameters $a$ and $b$ is close to 1 , which concludes the persistence of the conditional correlations between the series.

In Figure 2 we observe that dynamic correlations between the stock market and the bond market are positive at most surveyed periods, but roughly turn negative in early-2008 yet positive in late-2008. The following stages see persistently sharp fluctuations in addition to less periods with volatility shifts. The finding also indicates negative values at almost all study periods notably for the conditional correlation between the foreign exchange market and stock market. At many times, such as the early half 2006 and the entire 2008, the correlation changes from negative to positive. There is an increase in the dynamic correlation between exchange rate and interest rate in early 2008 after such a rather stable period with negative signs and values being nearly zero. Nevertheless, not so long after that the correlation becomes positive until the end of 2008, which is also received as a start of a process of constant sharp fluctuations in the correlation between the two markets as recorded with the other two correlation series. In addition, this result is complementary to the argument that increasing the interest rate would attract capital flows to a country, thus causing reduced exchange rates. At some points, however, it is suggested that both the interest rate and exchange rate tend to rise simultaneously. This is because given such an emerging market with prolonged deficits as Vietnam, the expectation channel is essential to investors' consideration of market activities. If there is an interest rate increase for one reason or another, it is commonly observed by investors that the market to invest in should be going to feel a particular shock, and consequently, hot money tends to swiftly flows out of the country. These results verify the importance of the expectation channel to cash inflows and outflows of developing countries. Additionally, particular characteristics of each correlation series are presented in Table 4 below. 


\section{Table 4}

Descriptive statistics of dynamic conditional correlation series

\begin{tabular}{lccc}
\hline & IR-VNI & USDVND-IR & USDVND-VNI \\
\hline Minimum & -0.7513 & -0.7690 & -0.8407 \\
Mean & 0.1863 & -0.0369 & -0.1643 \\
Maximum & 0.7768 & 0.6867 & 0.7467 \\
Standard deviation & 0.1632 & 0.1602 & 0.2659 \\
Skewness & -1.1263 & -0.2667 & 0.5323 \\
Kurtosis & 14.0213 & 13.1877 & 4.6362 \\
Jarque-Bera & $732.8975^{* * *}$ & $602.7545^{* * *}$ & $22.0706 * * *$ \\
ADF (with constant) & $-9.4089^{* * *}$ & $-10.0190^{* * * *}$ & $-10.2139 * * *$ \\
ADF (with constant and ten- & $-9.4715^{* * *}$ & $-9.9858^{* * *}$ & $-10.1748^{* * *}$ \\
dency) & & & \\
\hline
\end{tabular}

4.3. Effects of volatility shocks on correlations between market indicators

Within the scope of this current study, volatility change points can be identified when there exists a change in the structure of variance by using PELT, as earlier adopted by Zapodeanu et al. (2014). One important advantage of this method is that change points are determined endogenously (i.e. conditional on the data structure, not just the intuitive effect). Hence, the period at which the volatility is relatively large or small is determined to be the change point by the algorithm itself, not necessarily indicated by the financial crisis. The results of identification of change points (Figure 2, Table 4) suggest that PELT is capable of detecting periods of volatility shifts in association with factual events which have effects on volatilities of the data series. These identified periods include early- 2006 with the Vietnam's stock market in its spectacular growth and early- and late-2008 with the outbreak and spread of series of global financial crises witnessed first in the US. 


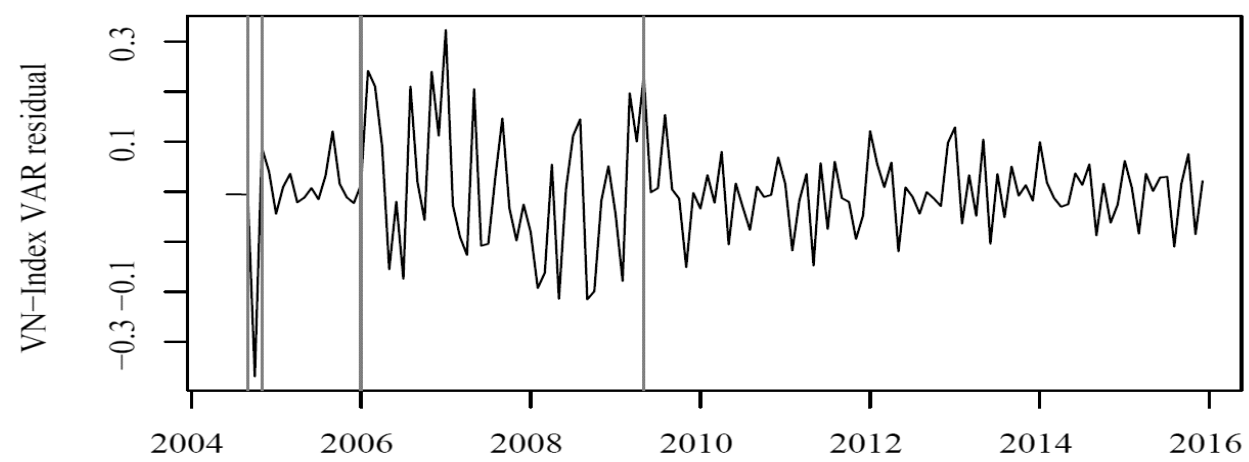

Volatility shifts detection

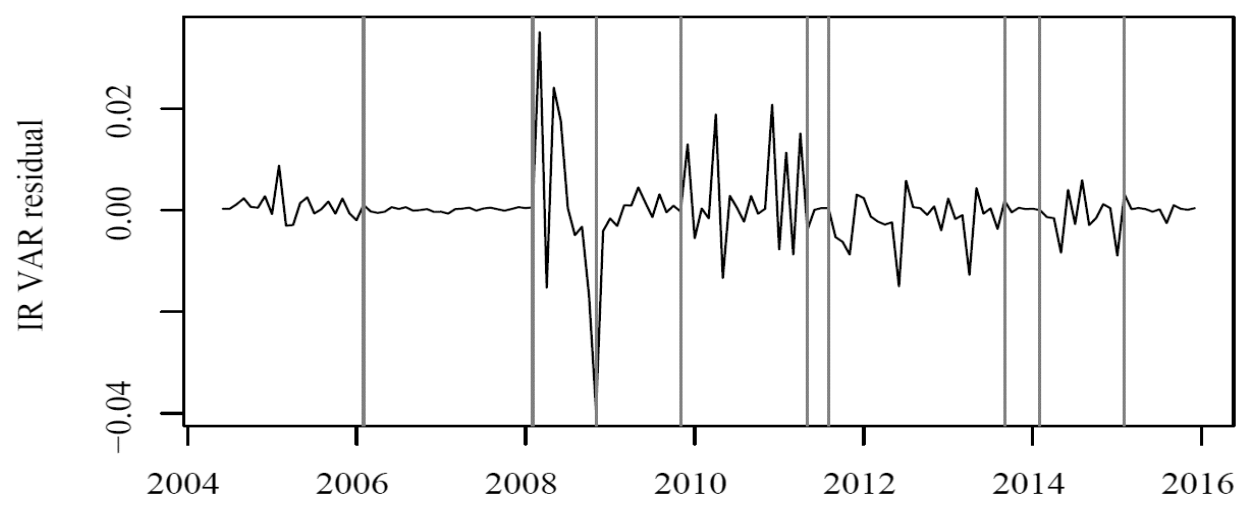

Volatility shifts detection

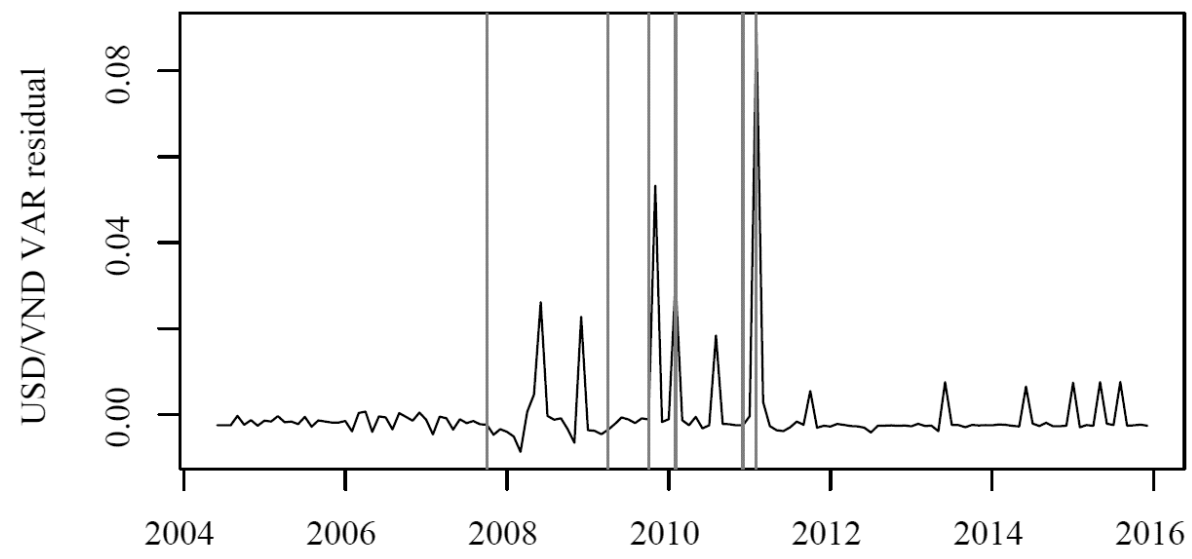

Volatility shifts detection

Figure 2. Identification of volatility shifts in residual series of VAR 
As depicted in Figure 3, during the periods in which the observed series show the up fluctuation (or the fluctuation around these points), a sudden change occurs in the correlation between the two series, i.e. the connection between the markets does respond to volatility shocks.

\section{Table 5}

Periods reflecting volatility shifts in residual series of VAR(1)

\begin{tabular}{clllllc}
\hline USDVND & & IR & & VNI & \\
\hline Period & Fluctuation & Period & Fluctuation & Period & $\begin{array}{c}\text { Fluc- } \\
\text { tuation }\end{array}$ \\
$09 / 2007$ & Down & $01 / 2006$ & Down & $08 / 2004$ & Down \\
$03 / 2009$ & Up & $01 / 2008$ & Up & $10 / 2004$ & Down \\
$09 / 2009$ & Up & $10 / 2008$ & Up & $01 / 2006$ & Up \\
$01 / 2010$ & Down & $10 / 2009$ & Up & $04 / 2009$ & Down \\
$11 / 2010$ & Up & $04 / 2011$ & Up & & \\
$01 / 2011$ & Down & $07 / 2011$ & Down & & \\
& & $08 / 2013$ & Down & & \\
& & $01 / 2014$ & Down & & \\
& & $01 / 2015$ & Down & & \\
\hline
\end{tabular}

Nonetheless, another interesting observation is that regarding even the same pair of markets, the directions of the response of correlation differ, i.e. at one volatility change point the correlation reveals the up fluctuation, whereas the fluctuation is down in the event of another change point.
Substantial and sudden changes can be seen, given the whole three lines illustrating correlations (early- and late-2008, revealing significantly large volatilities with their spillover effects on correlations between the studied markets). 

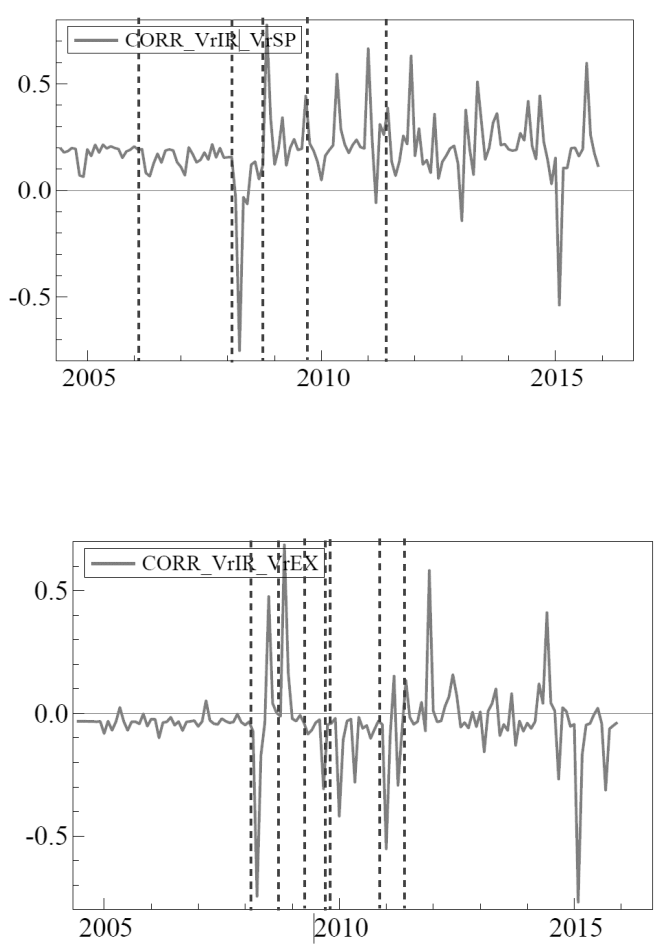

Looking further at the correlation trend between the markets in Figure 3, we can see that at some periods after the shocks, changes in the correlation do not rapidly fade away but occur for rather long time afterward. If this characteristic exists indeed, then the volatility shocks not only make sudden adjustments but also cause long-term changes in the structure of the correlation between the markets. Regressing the following equation will help clarify this observation:

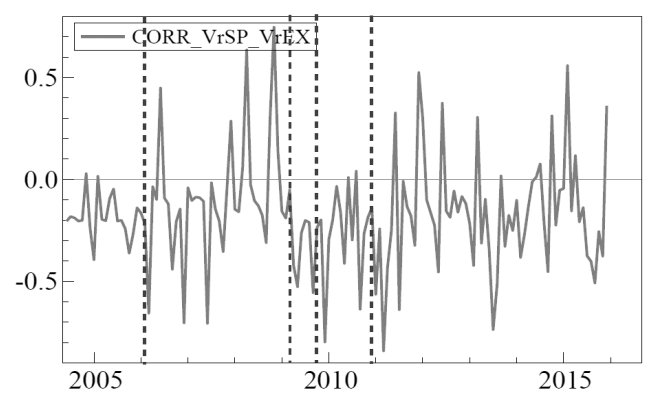

Figure 3. Conditional dynamic correlations between pairs of returns.

Note: The dashed lines denote positions of the up fluctuation in the correlation of the corresponding pairs of markets.

$$
\begin{aligned}
& \rho_{i j, t} \\
& =v_{0}+v_{1} \rho_{i j, t-1}+\sum_{k \in \text { the up volatility shock of } i \text { or } j} v_{k} D_{k} \\
& +\eta_{i j, t}
\end{aligned}
$$

Introduced to the above equation is the variable $\rho_{i j, t-1}$ to avoid the problem of autocorrelation. The dummy variables $D$ takes the value of 1 for the observations between the two adjacent up change points (from one change point to before the next) and the value of 0 for the observations in the other sections of the correlation series. Particularly, if one change point lies too close to the other(s), the first in the cluster will be selected. 


\section{Table 6}

Long-term effects of volatility shocks on dynamic correlations between the measured variables

\begin{tabular}{cccccc}
\hline & IR-VNI & \multicolumn{2}{c}{ IR-USDVND } & \multicolumn{2}{c}{ VNI-USDVND } \\
\hline Period & $v_{k}$ & Period & $v_{k}$ & Period & $v_{k}$ \\
\hline $01 / 2006$ & -0.0387 & $01 / 2008$ & -0.0339 & $01 / 2006$ & 0.0680 \\
& $(0.2848)$ & & $(0.5370)$ & & $(0.1970)$ \\
$01 / 2008$ & $-0.2093^{* * *}$ & $10 / 2008$ & $0.1741^{* *}$ & $03 / 2009$ & -0.1048 \\
& $(0.0003)$ & & $(0.0198)$ & & $(0.3504)$ \\
$10 / 2008$ & 0.0720 & $03 / 2009$ & -0.0135 & $09 / 2009$ & -0.1131 \\
& $(0.1339)$ & & $(0.8382)$ & & $(0.1437)$ \\
$10 / 2009$ & 0.0242 & $09 / 2009$ & $-0.0778 *$ & & \\
& $(0.5510)$ & & $(0.0887)$ & & \\
& & $11 / 2010$ & -0.0766 & & \\
& & & $(0.2946)$ & & \\
& & & & \\
\end{tabular}

Note: $(*),(* *)$, and $(* * *)$ denote significance at $10 \%, 5 \%$, and $1 \%$ respectively.

The estimated results of the regression model with dummy variables in Table 5 demonstrate the existence of statistically significant coefficients of the dummy variables for the pairs of interest rate and stock price as well as interest rate and exchange rate. This implies that the correlation at a particular period after the shock is significant, compared to those at other periods, and also suggests that abrupt changes in correlations between the markets caused by volatility shocks do not only occur in short terms but last for some times, or in other words, the responses are long-lasting. Accordingly, there should be more effort made by investors and policy makers in order to respond to those market volatility shocks.

\section{Conclusion}

This study analyzes the dynamic correlations between foreign exchange market, bond market, and stock market in Vietnam using novel econometric approaches. The $\operatorname{VAR}(p)-c \mathrm{DCC}-\operatorname{FIEGARCH}(1, d, 1)$ process indicates that these correlations are not stable but change over time and are 
statistically significant. As such, the positive association regarding the pair of bond and stock markets, together with many changes in the direction of correlation, shows that the discounted cash flow theory is not applicable for most of the surveyed periods. This result agrees with the findings of Rigobon and Sack (2003), Andersen et al. (2007), and Bale (2010). Also consistent with Sanchez (2008), the bond market and foreign exchange market are negatively correlated with instability as there are constantly vivid change points. The negative correlation between the stock market and foreign exchange market is not robust over time due to many more change points detected after 2006 and especially in 2008, which supports the findings of Roll (1992), Chow et al. (1997), and Soenen and Henninger (1988).

Next, in identifying the volatility change points of the return series using PELT approach, we find that volatility shocks have caused abrupt changes in the dynamic correlations between these markets. Still, directions of changes vary over time for the same pair of markets, implying that responses of the dynamic correlations to the shocks depend on time. More importantly, the paper suggests that their changes caused by the volatility shocks are not only significant in short terms but also persistent over a long time. Additionally, the results indicate the vulnerability of the
Vietnam's markets, clearly realized through the impacts of global crises on the associations between them.

\section{Implications}

The empirical results indicate that investors need to take into serious account market volatilities when deciding to invest in Vietnam's financial markets. Adjustments should be made to investment portfolios to ensure the returns corresponding to the desired level of risk since assets are correlated, and their correlations change over time, affected by volatility shocks. Investors assumed to have cross liabilities in these markets might not retain their distributed portfolios as the dynamic correlations between the markets at certain times do persist in the long run. Thus, it is important to consider a trade-off between allocation of investment as well as reduction of risk and low returns.

This is specifically essential to policy makers with the aim of stabilizing financial markets and the economy. Actually, the realities of the Vietnam's market in the post-crisis period reflect the extent to which adopted macro policies are influenced or become invalid: there have been severe depreciation of domestic currency, a surge in interest rate after stimulus packages, and double-digit inflation before several attempts were made to tighten 
and/or trade off the growth against an unstable market. Hence, when formulating macro policies, policy makers should carefully consider spillover effects in the markets to avoid unexpected impacts caused by adverse market performance. Sudden and forceful interventions in the money market made by the central bank during high volatility periods may cause great losses to foreign exchange reserves of the country

\section{References}

Aielli, G. P. (2013). Dynamic conditional correlation: On properties and estimation. Journal of Business and Economic Statistics, 31(3), 282-299.

Andersen, T. G., Bollerslev, T., Diebold, F. X., \& Vega, C. (2007). Real-time price discovery in global stock, bond and foreign exchange markets. Journal of International Economics, 73, 251277.

Auger, I. E., \& Lawrence, C. E. (1989). Algorithms for the optimal identification of segment neighborhoods. Bulletin of Mathematical Biology, 51(1), 39-54.

Baele, L. (2010). The determinants of stock and bond return comovements. The Review of Financial Studies, 23(6), 2374-2428.

Bautista, C. C. (2003). Interest rate-exchange rate dynamics in the Philippines: A DCC analysis. Applied Economics Letters, 10(2), 107-111.

Bianconi, M., Yoshino, J. A., \& de Sousa, M. O. M. (2013). BRIC and the US financial crisis: An empirical investigation of stock and bond markets. Emerging Markets Review, 14(2013), 76-109.

Bollerslev, T., \& Mikkelsen, H. O. (1996). Modeling and pricing long memory in stock market volatility. Journal of Econometrics, 73(1996), 151-184.

Branson, W. H. (1983). Macroeconomic determinants of real exchange risk. In R. J. Herring (Ed.), Managing foreign exchange risk. Cambridge University, Cambridge.

Chinn, M. D., \& Meredith, G. (2004). Monetary policy and long-horizon uncovered interest parity. IMF Staff. Papers, 51(3), 409-430.

Chow, E. H., Lee, W. Y., \& Solt, M. S. (1997). The exchange rate risk exposure of asset returns. The Journal of Business, 70(1), 105-123.

Dajcman, S., \& Festic, M. (2012). Interdependence between the Slovenian and European stock markets: A DCC-Garch analysis. Economic Research-Ekonomska Istraživanja, 25(2), 379-395.

Doong, S., Yang, S. Y., \& Wang, A. (2005). The dynamic relationship and pricing of stocks and exchange rates: Empirical evidence from Asian emerging markets. Journal of American Academy of Business, 7(1), 118-123.

Dornbush, R., \& Fisher, S. (1980). Exchange rates and the current account. The American Economic 
Review, 70(5), 960-971.

Edwards, A. W. F., \& Cavalli-Sforza, L. L. (1965). A method for cluster analysis. Biometrics, 21(2), 362-375.

Engle, R. F. (2002). Dynamic conditional correlation: A simple class of multivariate generalized autoregressive conditional heteroskedasticity models. Journal of Business and Economic Statistics, 20(3), 339-350.

Forbes, K. J., \& Rigobon, R. (2002). No contagion, only interdependence: Measuring stock market comovements. Journal of Finance, 57(5), 2223-2261.

Frankel, J. A. (1983). Monetary and portfolio-balance models of exchange rate determination. In J. S. Bhandari \& B. H. Putnam (Eds.), Economic interdependence and flexible exchange rates. MIT Press, Cambridge.

Hong, G., Kim, Y., \& Lee, B. S. (2011). Correlations between stock returns and bond returns: Income and substitution effects. Quantitative Finance, 14(11), 1-20.

Huynh, T. N., \& Nguyen, Q. (2013). The linkages between exchange rates, interest rates and stock prices in Ho Chi Minh City (in Vietnamese). Journal of Development and Integration, 11(21), $37-41$.

Joseph, N. L. (2002). Modelling the impacts of interest rate and exchange rate changes on UK stock returns. Derivatives use, Trading and Regulations, 7(4), 306-323.

Killick, R., Fearnhead, P., \& Eckley, I. A. (2012). Optimal detection of changepoints with a linear computational cost. Journal of the American Statistical Association, 107(500), 1590-1598.

Lee, C. H., Doong, S. C., \& Chou, P. (2011). Dynamic correlation between stock prices and exchange rates. Applied Financial Economics, 21(11), 789-800.

Lothian, R. L., \& Wu, L. (2011). Uncovered interest rate parity over the past two centuries. Journal of International Money and Finance, 30(2011), 448-473.

Nelson, D. B. (1991). Conditional heteroskedasticity in asset returns: A new approach. Econometrica, $59(2), 347-370$.

Phan, T. B. N., \& Pham, D. P. T. (2013). Analyzing the impacts of macro factors on Vietnam's stock market (in Vietnamese). Journal of Development and Integration, 8(18), 34-41.

Rigobon, R., \& Sack, B. (2003). Spillovers across US financial markets. NBER Working Paper No. 9640 issued in April 2003.

Roll, R. (1992). Industrial structure and comparative behavior of international stock indices. The Journal of Finance, 47(1), 3-41.

Sanchez, M. (2008). The link between interest rates and exchange rates: Do contractionary depreciations make a difference? International Economic Journal, 22(1), 43-61.

Scott, A. J., \& Knott, M. (1974). A cluster analysis method for grouping means in the analysis of variance. Biometrics, 30(3), 507-512. 
Sen, A., \& Srivastava, M. S. (1975). On tests for detecting change in mean. The Annals of Statistics, 3(1), 98-108.

Sensoy, A., \& Sobaci, C. (2014). Effects of volatility shocks on the dynamic linkages between exchange rate, interest rate and the stock market: The case of Turkey. Economic Modelling, 43, 448457.

Shiller, R. J., \& Beltratti, A. E. (1992). Stock prices and bond yields: Can their comovement be explained in terms of present value models? Journal of Monetary Economics, 30, 25-46.

Soenen, L., \& Henninger, E. (1988). An analysis of exchange rates and stock prices: The US experience between 1980 and 1986. Akron Business and Economic Review, 19, 7-16.

Tran Quang Huy. (2016). The linkage between exchange rates and stock prices: Evidence from Vietnam. Asian Economic and Financial Review, 6(7), 363-373.

Yang, J., Zhou, Y., \& Wang, Z. (2009). The stock-bond correlation and macroeconomic conditions: One and a half centuries of evidence. Journal of Banking \& Finance, 33(4), 670-680.

Zapodeanu, D., Cociuba, M., \& Petris, S. (2014). Inflation uncertainty and inflation in the case of Romania, Czech Republic, Hungary, Poland and Turkey. Procedia Economics and Finance, 15(2014), 1225-1234.

Zhao, H. (2010). Dynamic relationship between exchange rate and stock price: Evidence from China. Research in International Business and Finance, 24(2), 103-112. 